\title{
Irish Setter
}

National Cancer Institute

\section{Source}

National Cancer Institute. Irish Setter. NCI Thesaurus. Code C53877.

The Irish Setter is swift, with an acute sense of smell. It has a feathered, silky coat that comes in shades of chestnut to mahogany, sometimes with splashes of white on the chest and feet. The feet are well covered with hair. The chest is narrow. Height: 24-28 inches $(61-71 \mathrm{~cm}$.) Weight: 55-75 pounds $(25-34 \mathrm{~kg}$.) 